\title{
Metal-resin bonding mediated by epoxy monolith layer
}

\author{
Fai Uehara and Akikazu Matsumoto*
}

*Correspondence:

matsumoto@chem.

osakafu-u.ac.jp

Department of Applied

Chemistry, Graduate School

of Engineering, Osaka

Prefecture University, 1-1

Gakuen-cho, Naka-ku, Sakai,

Osaka 599-8531, Japan

\begin{abstract}
An epoxy monolith layer with porous structure is fabricated on the surface of a stainless steel (SUS) plate by polymerization induced phase separation process as the mediator for the bonding of SUS and various thermoplastic resin plates. Bonding strength is evaluated in the presence and absence of the epoxy monolith layer by a tensile lap shear test. The morphology of fracture surfaces is observed by scanning electron microscopy (SEM) in order to clarify the anchor effect of molten resins into the pores of the epoxy monoliths. The bonding strength values are calculated to be 1.2-2.7 MPa based on an apparent adhesion area for the bonding of SUS with polyethylene, polypropylene, polyoxymethylene and acrylonitrile-butadiene-styrene copolymer in the presence of the epoxy monolith mediator. These values are 2-30 times higher than those for direct metal-resin bonding. By the SEM observation, stretched needle-like structures were detected on the both fracture surfaces of the resins and the epoxy monoliths. The direct observation of the stretched debris out of the holes located at the monolith surfaces indicates the significant anchor effect for the present metal-resin bonding system. The bonding system mediated by the epoxy monolith layer is conveniently used for the bonding of dissimilar materials such as metals and resins without any special process and apparatus.
\end{abstract}

Keywords: Anchor effect, Dissimilar materials bonding, Epoxy monolith, Metal-resin bonding, Surface modification

\section{Background}

Tough and reliable bonding between dissimilar materials is one of the most important and challenging topics in the fields of adhesion and adhesives because metal components used for automobiles, aircrafts, and mechanical parts have increasingly been replaced by lightweight plastics and polymer composites during recent years [1, 2]. Mechanical interaction between rough surfaces accompanying an anchor effect as well as chemical bond formation such as reacting-type adhesives are important to obtain reliable bonding systems. For the dissimilar materials bonding such as metals and resins, closer contact and good affinity are required at an interface between both adherends with completely different surface properties [3-10]. Especially, the surface modification of metals has been considered to be a key process. In fact, many techniques by chemical conversion, chemical etching, plasma and laser treatments, as well as primer coating have been developed in order to realize high-strength adhesion for metal-resin bonding during injection, insertion, and transfer moldings and heat pressing processes $[1,2]$. On the other hand, the 
surface structures of polymers are readily controlled using several phase separation systems. Monolithic porous materials consisting of polymers or inorganic compounds have been prepared by thermally induced phase separation [11], non-solvent induced phase separation [12], and polymerization induced phase separation [13]. They are mainly used as separation filters, column packing materials for ion exchange and chromatography, catalyst supports, and electrical or thermal insulators due to their high strength and porosity [14-18]. Among them, it should be noted that Tsujioka and coworkers reported the fabrication of epoxy monoliths with a bicontinuous and highly porous structure and its application to the column packing materials for high-performance chromatographic and reacting systems [14]. The porous epoxy monoliths are expected to be applied to the modification of metal surfaces and adhesion to dissimilar materials including resins, but no report has ever been seen for the research on the dissimilar materials bonding using epoxy monoliths in the literature. In this study, we propose a new type of metal-resin bonding technique using monolithic epoxy resins as the adhesive layer manufactured on a metal surface by polymerization induced phase separation process. The bonding strengths were determined for the bonding system using a stainless steel (SUS) plate and polyethylene (PE), polypropylene (PP), polyoxymethylene (POM), and acrylonitrile-butadiene-styrene copolymer (ABS) as the thermoplastic resins in the presence of an epoxy monolith layer as the mediator for the robust bonding. The morphology of fracture surfaces was also investigated in order to discuss an anchor effect on this bonding system.

\section{Experimental procedures}

\section{General procedures}

Scanning electron microscopy observation was carried out using Keyence VE-9800 at acceleration voltage of $2.0-3.0 \mathrm{kV}$ after Au vapor deposition for the resin fracture surfaces and 0.8-1.0 kV without vapor deposition for the epoxy monolith surfaces on a SUS plate. The size and number of pores were evaluated based on the SEM images observed for the epoxy monolith surfaces on a SUS plate fabricated under various conditions. Epoxy layer thickness was determined using Peacock dial thickness Gauge gauge (Ozaki MFG Co., Ltd., Japan). Hot press was carried out using ASONE Co., Japan, AH-2003. The surface area of epoxy monolith was determined at $77 \mathrm{~K}$ using Microtrac BELL Co. BELPREP-vac-II and BELSORP-max by Brunauer-Emmett-Teller (BET) method. The tensile lap shear test was carried out using Shimadzu Autograph AGS-X 1 kN at a tensile rate of $1.0 \mathrm{~mm} / \mathrm{min}$. We prepared test pieces for the tensile lap shear measurement under the heat welding conditions at $140-170{ }^{\circ} \mathrm{C}$ for $60-90 \mathrm{~s}$, softly pressed at less than $1 \mathrm{MPa}$, as shown in Table 1 . The heat welding temperature and time for each resin were optimized according to the melting and glass transition temperatures of the used resins as the crystalline polymers (PE and $\mathrm{PP}$ ) and amorphous polymers (POM and $\mathrm{ABS}$ ), respectively. The heat welding conditions used in this study are shown in Table 1. Adhesion area was $10 \mathrm{~mm} \times 10 \mathrm{~mm}$. The moduli for the resin plates were determined by a tensile test at the tensile rate of $0.3 \mathrm{~mm} / \mathrm{min}$ in a range of $0.05-0.25 \%$ of the strain.

\section{Materials}

2,2-Bis(4-glycidyloxyphenyl)propane (BADGE), 4,4'-methylenebis(cyclohexylamine) (BACM), and poly(ethylene glycol) (PEG200, $\left.M_{\mathrm{n}}=200\right)$ were purchased from Tokyo 
Table 1 Thickness of the resin plates and heat welding conditions used in this study

\begin{tabular}{llll}
\hline Resin & Thickness of plate $(\mathbf{m m})$ & \multicolumn{2}{l}{ Heat welding conditions } \\
\cline { 3 - 4 } & & Temperature $\left({ }^{\circ} \mathbf{C}\right)$ & Time $(\mathbf{s})$ \\
\hline PE & 5 & 140 & 60 \\
PP & 4 & 170 & 60 \\
POM & 2 & 170 & 70 \\
ABS & 3 & 140 & 90 \\
\hline
\end{tabular}

Chemical Industry, Co., Ltd., Japan and used without further purification. The resin plates (thickness $=2-5 \mathrm{~mm}$ ) and SUS430 plate (thickness $=0.5 \mathrm{~mm}$ ) were purchased from ASONE Co., Japan and cut to a size of $10 \mathrm{~mm} \times 50 \mathrm{~mm}$.

\section{Preparation of epoxy monolith}

To a mixture of BADGE and BACM at a ratio of $2\left[\mathrm{NH}_{2}\right] /[$ epoxy $](\gamma$ value $)=0.83-1.55$, added was PEG200 (70 wt\%) as the porogen for the preparation of the epoxy monolith, according to the method described in the literature [14]. The flat epoxy layer was prepared at the condition of $\gamma=1.0$ without PEG200 in the presence of a few drops of ethanol for decreasing the viscosity of a reactant mixture. The mixture spread on a SUS plate was cured at $120^{\circ} \mathrm{C}$ for $20 \mathrm{~min}$. After PEG200 was removed with water, the epoxy monolith fabricated on a SUS plate was dried in vacuo at room temperature for $2 \mathrm{~h}$.

\section{Results and discussion}

The epoxy monoliths were prepared on a surface of the SUS plate using BADGE and BACM as the diepoxy and diamine compounds, respectively, in the presence of PEG200 as the porogen with curing at $120{ }^{\circ} \mathrm{C}$ for $20 \mathrm{~min}$, according to a procedure shown in Fig. 1. After the curing reaction, the test pieces were rinsed with water to remove PEG200, then dried in vacuo at room temperature. The thickness of the epoxy monolith layers was controlled by the amount of the reaction mixture spread on a SUS plate. We used the epoxy monoliths with thickness of 100-300 $\mu \mathrm{m}$ in this study. The SEM observation confirmed the formation of porous epoxy monoliths manufactured on the metal surface. It was revealed that the number and size of pores depended on the reaction conditions for the epoxy monolith fabrication, such as the ratio of the numbers of amino hydrogens and epoxy groups (i.e., the $\gamma$ value), the amount of the porogen, and the curing temperature. In the present study, the effect of the epoxy/amine ratio on the microporous structures was clarified under the constant temperature condition $\left(120^{\circ} \mathrm{C}\right)$ and the constant porogen content $(70 \mathrm{wt} \%)$. As a result, an increase in the $\gamma$ value from 0.8 to 1.2 led to an increase in the size and a decrease in the number of pores. A change in the pore size dependent on the $\gamma$ value is clearly seen in the SEM images in Fig. 2. From the plot of the pore diameters against the $\gamma$ values, we confirmed that the pore size reached $40 \mu \mathrm{m}$ at $\gamma=1.55$ (Fig. 3a) and that no porous structure was produced under the conditions at the $\gamma$ values less than 0.5 . Totally, the number of pores decreased according to the increase in the pore size, i.e., the $\gamma$ value, as shown in Fig. 3(b). These results were due to a change in the curing rate depending on the $\gamma$ value, as was already discussed in the previous paper [14]. Thus, we have confirmed that the pore size and number are conveniently controlled by an epoxy/amine ratio for the epoxy monolith fabrication. 


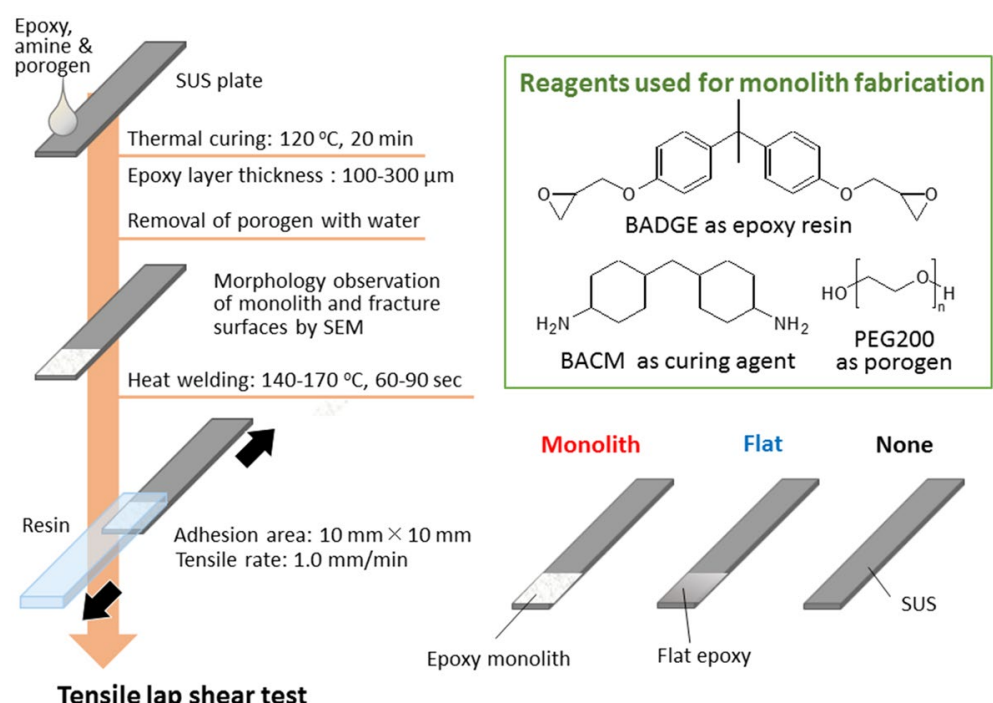

Fig. 1 Schematic experimental procedures. Preparation of test pieces for tensile lap shear test
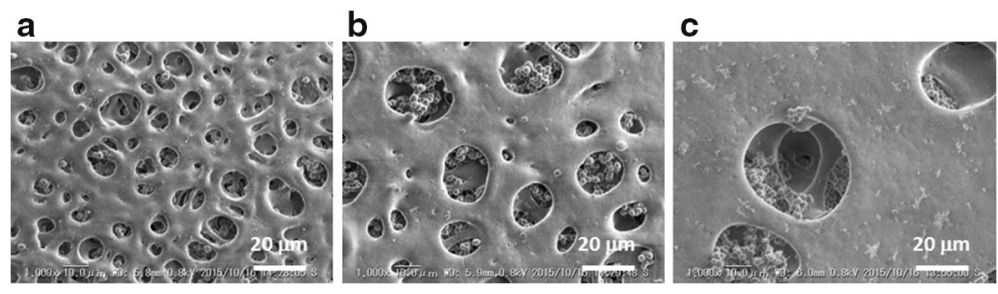

Fig. 2 SEM images of epoxy monolith surfaces. Epoxy monoliths were prepared under the conditions with various $\gamma$ values; $\mathbf{a} \gamma=0.8, \mathbf{b} \gamma=1.0$ and $\mathbf{c} \gamma=1.2$
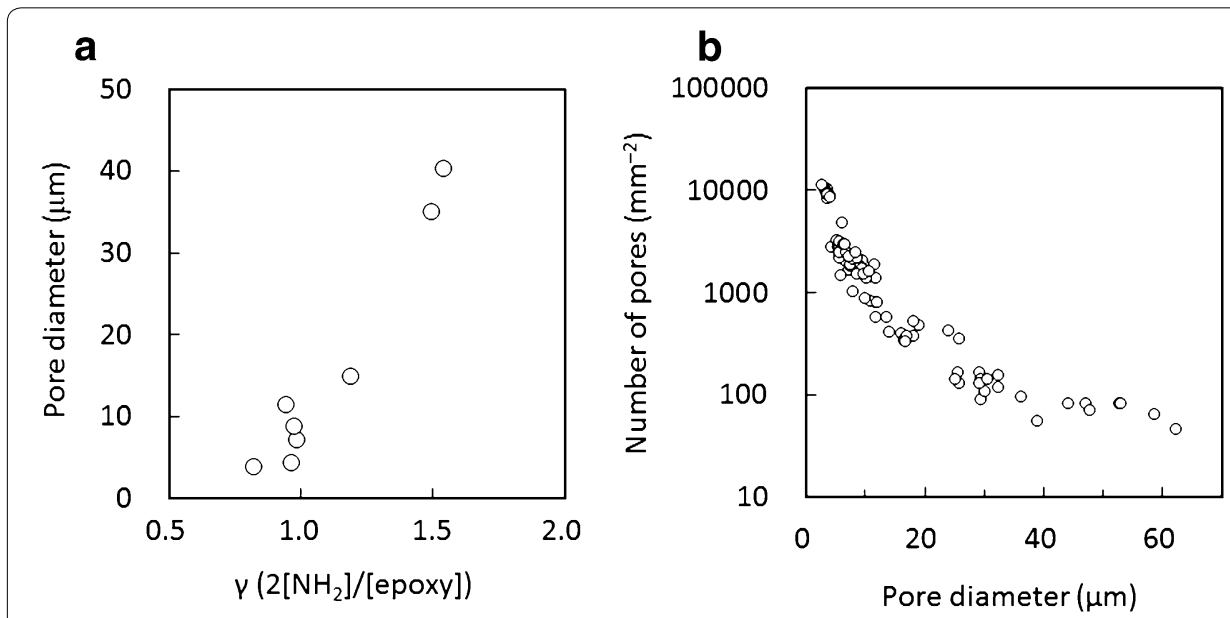

Fig. 3 Control of pore diameter and number. a Relationship between $\gamma$ value and average pore diameter and b change in the number of pores per unit area as a function of the pore diameter

Adsorption and desorption properties were evaluated by the BET method with $\mathrm{N}_{2}$ and $\mathrm{Kr}$ gasses at $77 \mathrm{~K}$ in order to confirm microporous and bicontinuous structures using the epoxy monoliths. The samples used the BET method were prepared under the 
condition of $\gamma=0.97$. On the basis of the experimental results of the absorption and desorption of the gasses in Fig. 4, specific surface areas were determined to be 0.58 and $0.66 \mathrm{~m}^{2} / \mathrm{g}$ for the experiments using $\mathrm{N}_{2}$ and $\mathrm{Kr}$, respectively. These values were similar to those for similar epoxy monoliths reported by Tsujioka and coworkers in the literature [14]. During the formation of a bicontinuous and highly porous epoxy monolith structure via a reaction-induced phase separation mechanism, the epoxy-rich phase should contain a small amount of PEG200 and consequently small pores would be produced by the subsequent solvent etching process. Such small pores were not detected by SEM under the conditions shown in this study, but it was probably counted by the BET method. The both results obtained by the SEM observation and the BET experiments were not directly compared with each other in this study. We also determined a porosity value from the result of density measurement. The porosity was $32 \%$ for the monolith prepared under the conditions at $\gamma=0.97$ (the sample same as that used for the BET experiments). In this study, we mainly used the epoxy monoliths with the average pore diameters of 4-26 $\mu \mathrm{m}$ for the following tensile lap shear test, which were prepared under the conditions of the $\gamma$ value in a range of $0.95-1.04,70 \mathrm{wt} \%$ of the porogen content in feed, and curing at $120^{\circ} \mathrm{C}$ for $20 \mathrm{~min}$.

The tensile test was carried out using the test pieces with and without the epoxy monolith layer between the SUS and resin plates. The flat epoxy surface was also prepared as the reference in the absence of porogen under the same curing conditions. We compared the lap shear strength values for three different bonding specimens, i.e., metalresin bonding via an epoxy monolith layer, metal-resin bonding via a flat epoxy layer, and direct metal-resin bonding. The representative curves for the tensile tests using PE, PP, POM, and ABS as the resins with or without epoxy monolith mediator are shown in Fig. 5. The obtained results are summarized in Table 2 and Fig. 6 . The adhesion strength values of $2.00 \pm 0.22$ and $1.36 \pm 0.20 \mathrm{MPa}$ were obtained for the bonding with PE and $\mathrm{PP}$, respectively, by the use of the epoxy monolith mediator. They were two or three times larger values compared with the strength values for the direct metal-resin bonding. The epoxy monolith mediator was also valid for other high-performance resins such as POM and ABS; the bonding strength values were $1.22 \pm 0.57$ and $2.66 \pm 0.74 \mathrm{MPa}$,

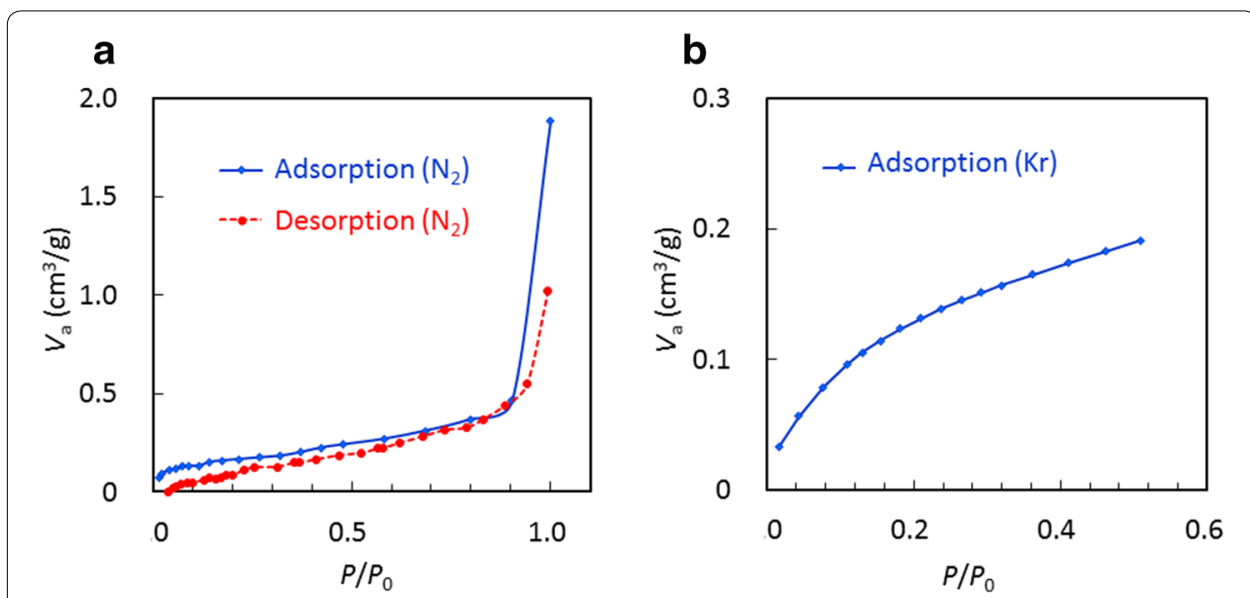

Fig. 4 BET adsorption and desorption isotherm. $\mathbf{a} \mathrm{N}_{2}$ and $\mathbf{b} \mathrm{Kr}$ gasses at $77 \mathrm{~K}$ for epoxy monolith prepared under the condition of $\gamma=0.97$ 


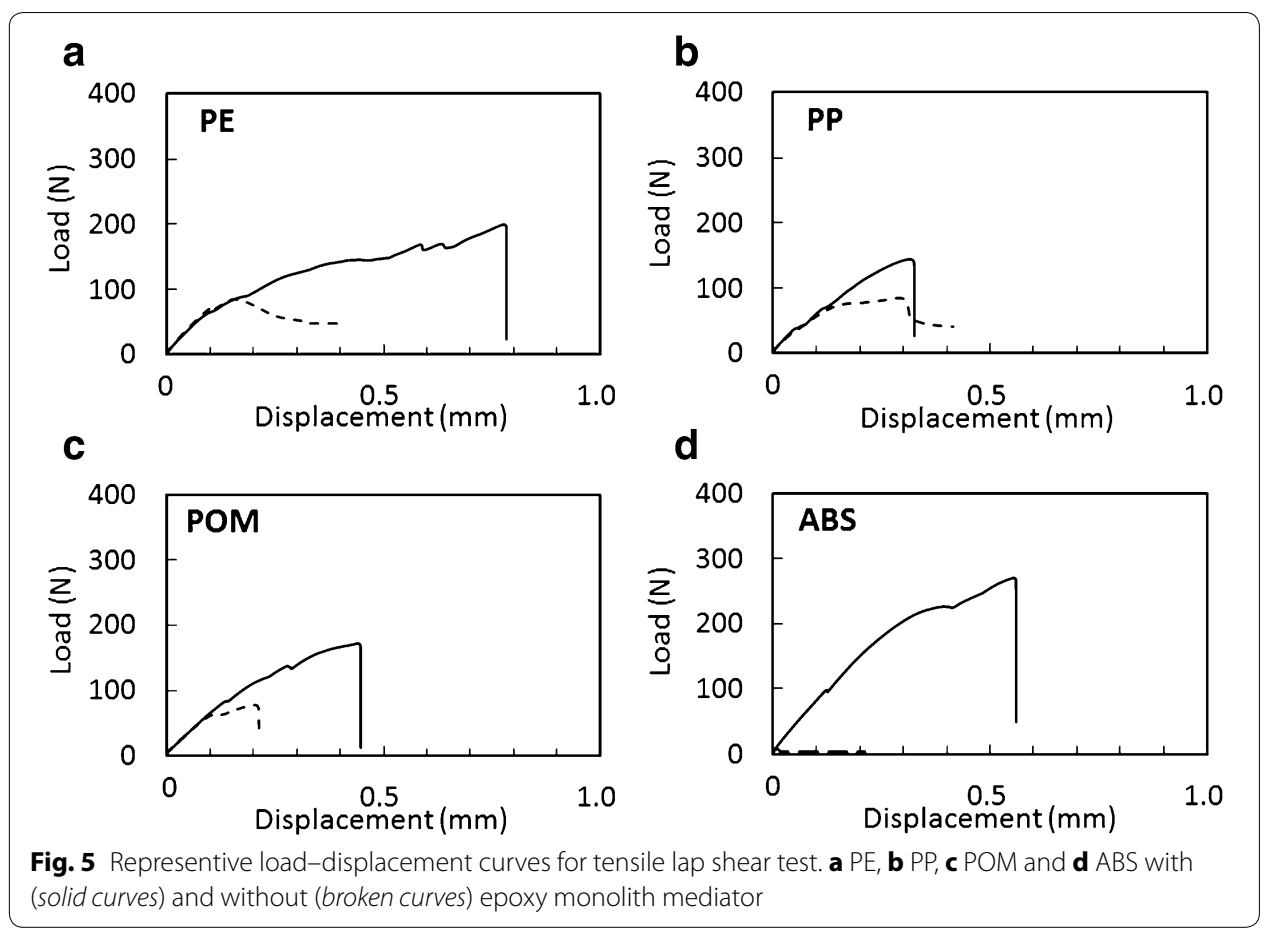

Table 2 Bond strength of metal-resin specimens with or without epoxy monolith mediator

\begin{tabular}{llllllll}
\hline Resin & \multicolumn{2}{l}{$\begin{array}{l}\text { Bond strength based on apparent } \\
\text { adhesion area }\left(\mathbf{1 0 0} \mathbf{~ m m}^{\mathbf{2}} \text { ) }(\mathbf{M P a})\right.\end{array}$} & $\begin{array}{l}\text { Imaginary bond } \\
\text { strength based } \\
\text { on pore cross-sec- } \\
\text { tion area (MPa) }\end{array}$ & $\begin{array}{l}\text { Break- } \\
\text { ing strain } \\
\text { for SUS-resin } \\
\text { specimen (\%) }\end{array}$ & $\begin{array}{l}\text { Modulus } \\
\text { for SUS- } \\
\text { resin speci- } \\
\text { men (GPa) }\end{array}$ & $\begin{array}{l}\text { Modulus } \\
\text { for resin } \\
\text { plates } \\
\text { (GPa) }\end{array}$ \\
monolith & $\begin{array}{l}\text { Via flat } \\
\text { epoxy }\end{array}$ & $\begin{array}{l}\text { Direct } \\
\text { bonding }\end{array}$ & & & & & \\
\hline PE & $2.00 \pm 0.22$ & $\sim 0$ & $0.63 \pm 0.21$ & $28.2 \pm 5.5$ & $2.3 \pm 0.6$ & $0.4 \pm 0.1$ & 0.7 \\
PE & $2.20 \pm 0.31$ & $\sim 0$ & $0.63 \pm 0.21$ & - & $1.6 \pm 0.5$ & $0.4 \pm 0.02$ & 0.7 \\
PP & $1.36 \pm 0.20$ & $\sim 0$ & 0.85 & $12.6 \pm 3.4$ & $1.2 \pm 0.4$ & $0.4 \pm 0.1$ & 0.9 \\
POM & $1.22 \pm 0.57$ & $\sim 0$ & 0.52 & $17.0 \pm 6.4$ & $0.9 \pm 0.4$ & $0.8 \pm 0.3$ & 1.3 \\
ABS & $2.66 \pm 0.74$ & $\sim 0$ & 0.08 & $35.3 \pm 20.6$ & $1.4 \pm 0.5$ & $0.8 \pm 0.1$ & 1.0 \\
\hline
\end{tabular}

a Epoxy with a connected-globule structure was used instead of epoxy monolith with a bicontinuous structure

respectively. The latter was much higher than that for the direct resin-metal bonding (0.08 MPa). Apparent breaking strain and modulus values for the SUS-rein adhesion specimens were $0.9-2.3 \%$ and $0.4-0.8 \mathrm{GPa}$, respectively. The latter values were correlated to the moduli for the resins themselves $(0.7-1.3 \mathrm{GPa})$. In this study, we confirmed no bonding property between the all used resins and the cured epoxy with a flat surface containing no porous structure $(\sim 0 \mathrm{MPa})$. We also attempted the bonding of SUS and resin plates using in situ curing with BADGE and BACM upon heating, but it failed again. In general, unmodified epoxy adhesives are not available for the adhesion of polyolefins and nonpolar thermoplastics, while various kinds of epoxy adhesives are conveniently used for metal bonding because of their highly hydrophilic structure.

Interfacial failures between the monolith and the resin were mainly observed due to the robust interaction between the metal and the epoxy layer as well as the toughness of the epoxy resin. Figure 7 shows the SEM images of the fracture surfaces after the 


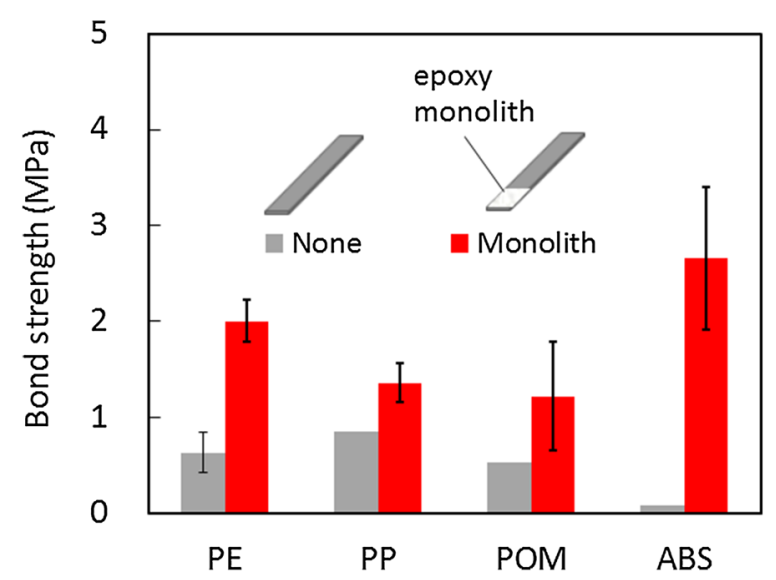

Fig. 6 Comparison of bond strength values. For tensile lap shear test using various resins with and without epoxy monolith mediator

tensile lap shear test using epoxy monoliths. A large number of stretched needle-like structures were observed on the both surfaces of the resins and the epoxy monoliths. The fashion of the elongation of the resins at the ductile failure positions was dependent on the mechanical property of the resins. Highly stretched deformation of the debris was observed for the fracture surfaces of the PE, PP, and POM plates, while stomp-like debris were detected for the surface of the ABS plate. The most distinguished enhancement of the bonding strength for the ABS resin in the presence of the epoxy monolith layer, as shown in Fig. 6, was possibly related to the characteristics of the resin. In general, conventional ABS resins have a complicated graft structure with microphase separation, and it may contribute to the appearance of their high-strength properties. It is noted that the direct observation of the stretched debris out of the holes located at the monolith surfaces undoubtedly indicates the significant anchor effect for the present metal-resin bonding system. The penetration of the molten resins into a deep area of the epoxy monoliths during the heat welding process is well interpreted by the characteristics of the epoxy surfaces with a high free energy and the thermoplastic resins with a low free energy and high fluidity. From the SEM observation, we directly confirmed stress

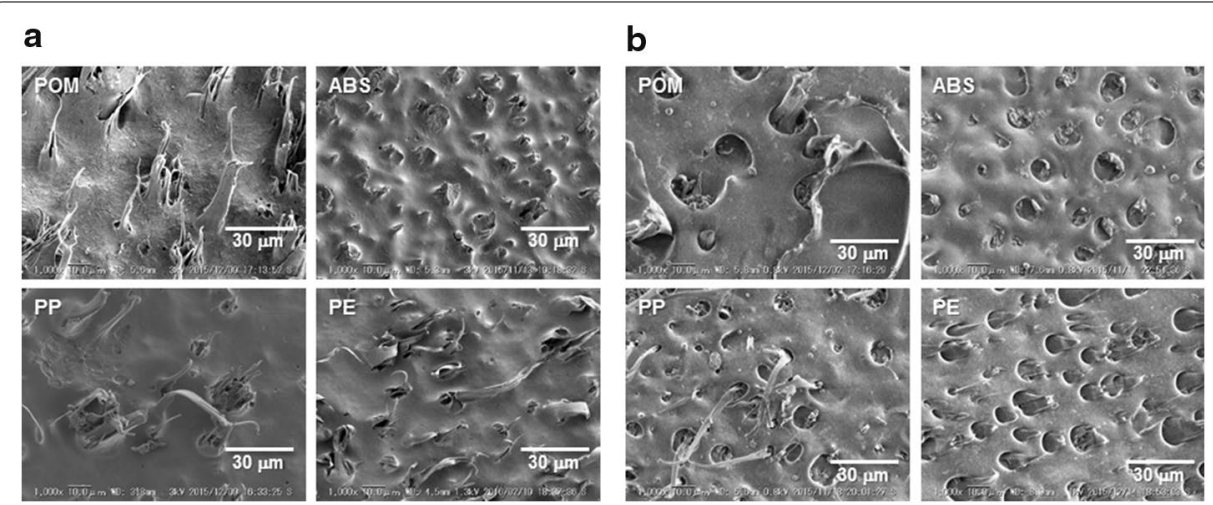

Fig. 7 SEM images of fracture surfaces. a Resin fracture surfaces and $\mathbf{b}$ epoxy monolith fracture surfaces after tensile lap shear test for specimens with various resins. $\gamma=0.94-1.04$ 


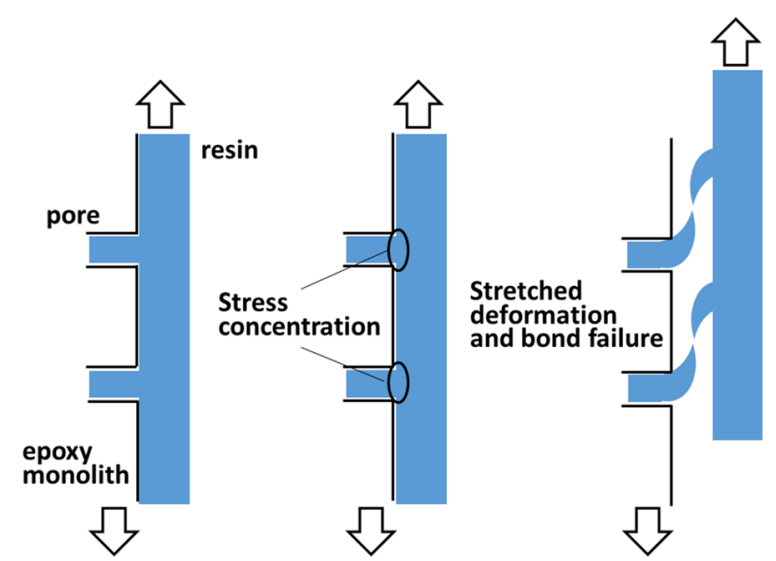

Fig. 8 Schematic model for failure of epoxy monolith bonding. The bond failure is induced by stress concentration at the epoxy monolith and resin interfaces

concentration against the applied shear force at local positions near the pores and the deformation of the resins at the interfaces. Figure 8 shows a model for the bond failure of the metal-resin specimen induced by the stress concentration at the epoxy monolith and resin interfaces. We evaluated imaginary strength values based on the pore crosssection area, but not based on the apparent adhesion area $\left(100 \mathrm{~mm}^{2}\right)$. The calculated bond strength values were in a range of 12.6-35.3 MPa as summarized in Table 2, being comparable to the maximum strength values reported in the literature for these resins (20-70 MPa) [19].

According to the bonding mechanism proposed in this study, the bonding strength was supposed to depend on the morphology of the epoxy surfaces. Another epoxy layer with a different porous structure can be manufactured by a similar polymerization induced phase separation procedure using the identical materials. It was reported that a connected-globules structure was produced despite the bicontinuous monolith structure depending on the reaction conditions [14], and that the cured epoxy phase with a connected-globules structure was precipitated from semistable region between bimodal and spinodal curves in a phase diagram for the mixture of the same epoxy, amine, and porogen, while bicontinuous monolith structures were constructed from a composition inner the spinodal curve as the unstable state [14]. We successfully prepared another kind of epoxy layer with a connected-globule surface structure and the tensile lap shear
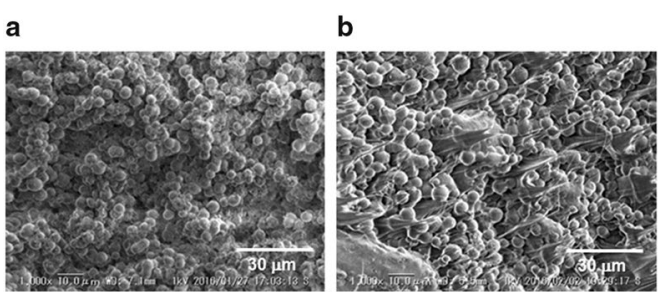

C

Fig. 9 SEM images of epoxy with a connected-globule structure. a Epoxy surface as prepared, b epoxy fracture surface and $\mathbf{c}$ PE fracture surface after tensile lap shear test using epoxy with a connected-globule structure 
test was carried out using it. As a result, a high strength value $(2.20 \pm 0.31 \mathrm{MPa})$ was obtained for the connected-globule surface, being similar to those for the bicontinuous monolith surfaces. The roughness of the epoxy surfaces and the presence of pour structure may contribute to an increase in the strength. The expanded PE debris were actually observed for the both fracture surfaces of PE and the epoxy layer, as shown in Fig. 9. We are now continuing the studies on a relationship between the micropore structure and their sizes of the epoxy monoliths and the bonding strength, as well as the detailed mechanism of this bonding system by manufacturing the epoxy monoliths with various surface structures.

\section{Conclusions}

In this paper, we demonstrated a new metal-resin bonding method using epoxy monolith as the adhesive mediator between metal and resin adherends. The anchor effect for the robust bonding of dissimilar materials was directly confirmed by the SEM observation of the epoxy monolith and resin fracture surfaces. The epoxy monoliths have recently been reported to be useful as the separation materials due to their bicontinuous and highly porous structure. In this study, we proposed the dissimilar materials bonding using the epoxy monolith layers on a metal surface in order to effectively induce an anchor effect during the bonding with various resins. This method requires only conventional chemicals and simple procedures for the bonding process and is expected for application to various types of materials and bonding processes in future. Thus, it has been demonstrated that the bonding system with the epoxy monolith mediator is conveniently used for the bonding of dissimilar materials such as metals and resins without any special process and apparatus.

Authors' contributions

AM designed the study and prepared the manuscript. FU carried out all the experiments for materials preparation and measurements. Both authors read and approved the final manuscript.

\section{Acknowledgements}

The authors thank to Prof. Masaya Matsuoka and Dr. Yu Horiuchi, Osaka Prefecture University for the surface area determination by the BET method.

\section{Competing interests}

The authors declare that they have no competing interests.

Received: 9 September 2016 Accepted: 23 November 2016

Published online: 28 November 2016

\section{References}

1. Toray Research Center, editor. Dissimilar materials bonding technology. 2014 ed. Otsu: Toray Research Center; 2014. pp 1-273 (in Japanese).

2. Technical Information Institute Co Ltd., editor. Adhesion and bonding technology of resins and metals. (Gijutsu-Joho Kyokai). Chapter 3. Tokyo: Technical Information Institute Co Ltd.; 2012. pp 77-190 (in Japanese).

3. Yamabe H. Stabilization of the polymer-metal interface. Prog Org Coat. 1996;28:9-15.

4. Bouchet J, Roche AA. The formation of epoxy/metal interphases: mechanisms and their role in practical adhesion. J Adhes. 2002;78:799-830.

5. Lee H-Y, Qu J. Microstructure, adhesion strength and failure path at a polymer/roughened metal interface. J Adhes Sci Technol. 2003;17:195-215.

6. Packham DE. Surface energy, surface topography and adhesion. Int J Adhes Adhes. 2003;23:437-48.

7. da Silva LFM, Adams RD. Techniques to reduce the peel stresses in adhesive joints with composites. Int J Adhes Adhes. 2006:27:227-35. 
8. Kim W-S, Yun I-H, Lee J-J, Jung H-T. Evaluation of mechanical interlock effect on adhesion strength of polymer-metal interfaces using micro-patterned surface topography. Int J Adhes Adhes. 2010;30:408-17.

9. Horiuchi S, Hanada T, Miyamae T, Yamanaka T, Osumi K, Ando N, Naritomi M. Analysis of metal/plastic interfaces by energy-filtering transmission electron microscopy. J Adhes Soc Jpn. 2012;48:322-30.

10. Shimamoto K, Sekiguchi Y, Sato C. Effects of surface treatment on the critical energy release rates of welded joints between glass fiber reinforced polypropylene and a metal. Int J Adhes Adhes. 2016;67:31-7.

11. Nishi T, Wang TT, Kwei TK. Thermally induced phase separation behavior of comparable polymer mixtures. Macromolecules. 1975;8:227-34.

12. Bonyadi S, Chung TS, Krantz WB. Investigation of corrugation phenomenon in the inner contour of hollow fibers during the non-solvent induced phase-separation process. J Mem Sci. 2007;299:200-10.

13. Kaji H, Nakanishi K, Soga N. Polymerization-induced phase separation in silica sol-gel systems containing formamide. J Sol-Gel Sci Technol. 1993;1:35-46.

14. Tsujioka N, Ishizuka N, Tanaka N, Kubo T, Hosoya K. Well-controlled 3D skeletal epoxy-based monoliths obtained by polymerization induced phase separation. J Polym Sci Part A Polym Chem. 2008;46:3272-81.

15. Svec F, Fréchet JMJ. New designs of macroporous polymers and supports: from separation to biocatalysis. Science. 1996;273:205-11.

16. Nguyen AM, Irgum K. Epoxy-based monoliths. A novel hydrophilic separation material for liquid chromatography of biomolecules. Chem Mater. 2006:18:6308-15.

17. Matsukawa K, Mitamura K, Watase S, Ishizuka N. Present state of flow reactors and development of novel column reactor. J Syn Org Chem Jpn. 2015;73:498-503.

18. Urban J. Current trends in the development of porous polymer monoliths for the separation of small molecules. J Sep Sci. 2016:39:51-68.

19. Mark JE. Polymer data handbook. 2nd ed. Oxford: Oxford University Press; 2009.

\section{Submit your manuscript to a SpringerOpen ${ }^{\circ}$ journal and benefit from:}

- Convenient online submission

\section{- Rigorous peer review}

- Immediate publication on acceptance

- Open access: articles freely available online

- High visibility within the field

Retaining the copyright to your article

Submit your next manuscript at $\boldsymbol{\nabla}$ springeropen.com 